\title{
THE IMPORTANCE OF CONFORMATION OF THE TETRAHEDRAL INTERMEDIATE IN THE HYDROLYSIS OF ESTERS AND AMIDES
}

\author{
PierRe Deslongchamps \\ Département de Chimie, Université de Sherbrooke, \\ Sherbrooke, Québec, Canada J1K 2R1
}

\begin{abstract}
A new stereoelectronic theory for the cleavage of the tetrahedral intermediate in the hydrolysis of esters and amides is presented. In this new theory, the precise conformation of the intermediate hemi-orthoester or hemi-orthoamide controls the nature of the hydrolysis products. It is postulated that the breakdown of a conformer of a tetrahedral intermediate depends upon the orientation of the lone pair orbitals of the heteroatoms. Specific cleavage of a carbonoxygen or a carbon-nitrogen bond in any conformer is allowed only if the other two heteroatoms (oxygen or nitrogen) each have an orbital oriented antiperiplanar to the leaving $O$-alkyl or $N$-alkyl group. Experimentally, the oxidation of acetals by ozone and the acid hydrolysis of a series of cyclic orthoesters demonstrates clearly that there is indeed a stereoelectronic control in the cleavage of hemi-orthoesters. Similarly, a study of the basic hydrolysis of a variety of $N, N$-dialkylated imidate salts shows that the same stereoelectronic control is operating in the cleavage of hemi-orthoamides.
\end{abstract}

It is generally accepted that the most common mechanism for the hydrolysis of esters and amides proceeds through the formation of a tetrahedral intermediate. The conformation of this tetrahedral intermediate (hemiorthoester from ester and hemi-orthoamide from amide) has never yet been considered to be an important parameter in order to obtain a better understanding of the hydrolysis reaction ${ }^{1}$. We wish to report a new stereoelectronic theory in which the precise conformation of the tetrahedral intermediate plays a major role.

In this new theory, the nature of the products formed from the hydrolysis of an ester or amide depends upon the conformation of the tetrahedral hemiorthoester or hemi-orthoamide intermediate. It is further postulated that the breakdown of a tetrahedral conformer depends upon the orientation of the lone pair orbitals of the heteroatoms. A specific cleavage of a carbon-oxygen or a carbon-nitrogen bond is allowed only if the other two heteroatoms (oxygen or nitrogen) of the tetrahedral intermediate each have an orbital oriented antiperiplanar to the leaving $O$-alkyl or $N$-alkyl group.

This new theory originated from our study on the oxidation of acetals to 
esters with ozone ${ }^{2}$. We will first describe this reaction and then disclose the theory of stereoelectronic control in the cleavage of hemi-orthoesters ${ }^{3}$ which provides an explanation for the formation of products in the ozonolysis of acetals. We will then furnish independent experimental evidence that specific cleavage of hemi-orthoesters does indeed take place, based upon a study of the acid hydrolysis of cyclic mixed orthoesters. Finally, the theory of stereoelectronic control in the cleavage of hemi-orthoamides will also be presented ${ }^{4}$. Our study on the basic hydrolysis of imidate salts will confirm that stereoelectronic control in the cleavage of hemi-orthoamides does occur.

\section{OZONOLYSIS OF ACETALS}

We reported in 1971 that ozone reacts in a completely specific fashion with the acetal function derived from an aldehyde to give the corresponding ester and alcohol. This reaction is a general one; the nature of the alkyl groups

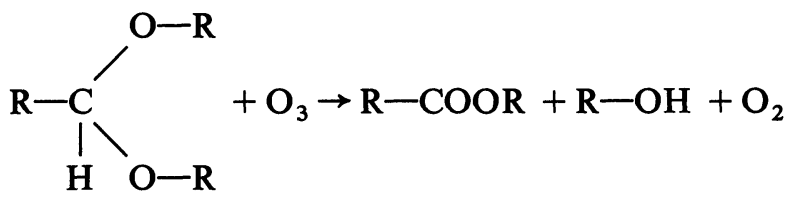

of the acetal function does not influence the final result, and this reaction proceeds in essentially quantitative yield. However, we have found that there is a tremendous difference in the rate of reaction depending on the nature of the acetal function (Figure 1); cyclic acetals react much faster (a few minutes at $-78^{\circ}$ ) than the acyclic ones $\left(\simeq 15 \mathrm{~h}\right.$ at $\left.-78^{\circ}\right)$. The observed large difference in rates of oxidation of cyclic as compared to acyclic acetals was the first indication that there was a direct relationship between the conformation of the acetal function and its reactivity toward ozone. We believe that this reaction proceeds via the insertion of ozone into the $\mathrm{C}-\mathrm{H}$ bond of the acetal forming an intermediate such as 1 or 2, which can then break down to give the reaction products, the ester and the alcohol.

We next investigated the oxidation of acetals where the OR groups were not identical. It was of interest to examine such substrates because a tetrahedral intermediate formed during the oxidation of such unsymmetrical acetals, could decompose in two different ways. For instance, a substrate such as 3 (Figure 2) should lead to an intermediate such as 4 . Intermediate 4 could decompose to give the hydroxy-ester 5, or the lactone 6, plus the alcohol. We found experimentally that ozone reacts smoothly with tetrahydropyranyl ethers in a completely specific manner, yielding the hydroxy-ester 5 exclusively. No trace of lactone 6 could be detected. Thus, it can be immediately concluded that if the ozonolysis reaction proceeds through the formation of hemiorthoester 4 or its equivalent, this intermediate must decompose in a very specific manner!

After completing our work on the simple tetrahydropyranyl ethers, the next logical step was to study this new reaction on tetrahydropyranyl ethers which possessed a rigid chair conformation. Consequently, the oxidation of a series of conformationally rigid $\alpha$ - and $\beta$-methyl glycopyranosides was 
HYDROLYSIS OF ESTERS AND AMIDES

$\underset{\mathrm{H}}{\mathrm{R}} \underset{\mathrm{C}^{\mathrm{C}} \mathrm{OCH}_{3}}{\mathrm{OCH}_{3}}+\mathrm{O}_{3} \underset{15 \mathrm{~h},-78^{\circ}}{\longrightarrow} \mathrm{R}-\mathrm{COOCH}_{3}+\mathrm{CH}_{3} \mathrm{OH}$

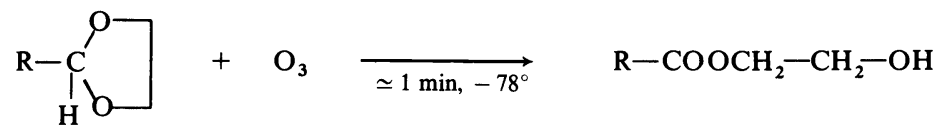
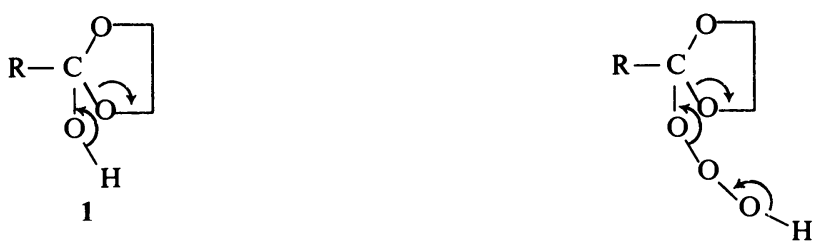

2

Figure 1.<smiles>CCOC1CCCCO1</smiles>

3<smiles>CCOC1(O)CCCCO1</smiles>

4<smiles>CCOC(=O)CCCCO</smiles>

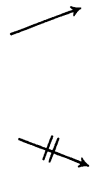<smiles>CC[O+]=O</smiles>

6

5

Figure 2.

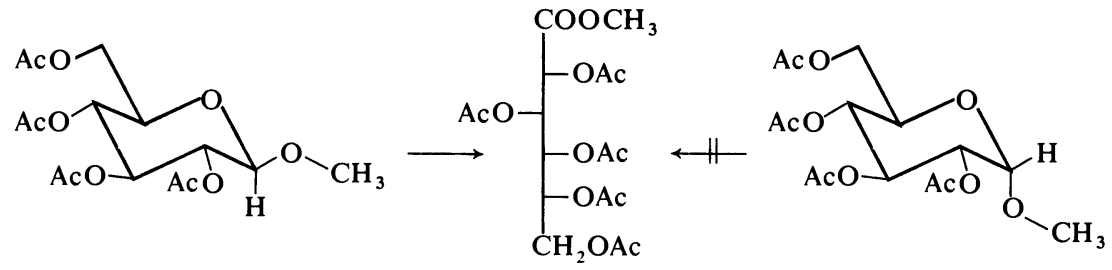

Figure 3.

undertaken. We found a very interesting result : the $\beta$ anomers were smoothly oxidized by ozone while the $\alpha$ anomers were recovered unchanged. For example, methyl 2,3,4,6-tetra- $O$-acetyl- $\beta$-D-glucopyranoside was converted 
into methyl 2,3,4,5,6-penta- $O$-acetyl-gluconate, while the corresponding $\alpha$ anomer was shown to be completely unaffected under the same reaction conditions (Figure 3).

The preceding results can be summarized in the following way: cyclic acetals (7) react readily with ozone, while acyclic acetals (10) react slowly; $\beta$-glycosides (8) are reactive, but $\alpha$-glycosides (9) are inert (Figure 4). These

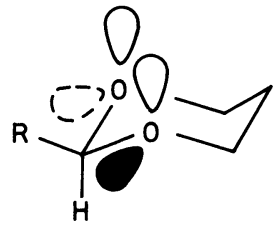

7

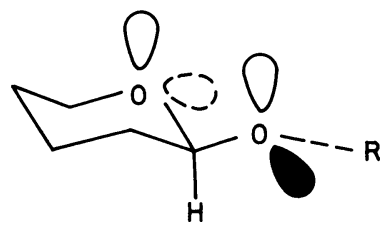

8

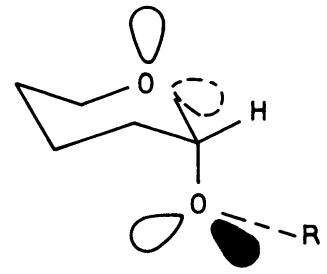

9

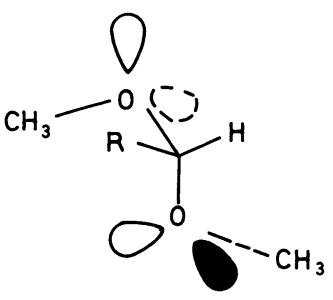

10

Figure 4.

results suggested that there was a relationship between the conformation of the acetal function and its reactivity toward ozone. After viewing models of the compounds under consideration, we made the following proposal: any reactive conformer must have on each oxygen atom a lone pair orbital oreiented antiperiplanar to the $\mathrm{C}-\mathrm{H}$ bond of the acetal function ${ }^{2}$. This requirement was met in the dioxolane acetals (7) and the most stable rotamer of the $\beta$ glycosides $(8)^{5}$. In an $\alpha$-glycoside, which can be represented as its favoured rotamer by structure 9 , the ring oxygen orbitals are not oriented antiperiplanar to the $\mathrm{C}-\mathrm{H}$ bond ; it is the ring carbon-oxygen bond which is antiperiplanar. The lone pair orbitals of the ring oxygen in an $\alpha$-glycoside (regardless of the rotamer) are never available, indicating that the oxidation does not proceed at a detectable rate if only one oxygen has one orbital properly oriented. Furthermore, acyclic dialkoxy acetals are known ${ }^{6}$ to exist in one preferred conformation (10) which is identical to the favoured rotamer of an $\alpha$-glycoside (9). This is quite normal because this conformer is the only one which avoids the anomeric effect ${ }^{5}$. Conformer 10 is inert toward ozone. In order to react with ozone, the dialkoxy acetals must adopt another conformation which has 
proper orbital orientation. This is possible with the dialkoxy acetals but impossible with chair-rigid- $\alpha$-glycosides. However, any reactive conformer of the dialkoxy acetal will be present only in a very small amount at equilibrium because such a conformer has to overcome the anomeric effect which exists when two lone pair orbitals are in a 1,3-syn-periplanar arrangement $\dagger$. Consequently, the reaction rate, which is dependent upon the concentration of the reactive conformer, is going to be low.

It is clear at this stage of our investigation that the postulate of the orientation of the lone pairs had to be verified in a more rigorous manner. Consequently, we had to consider all the possible gauche conformers that an acetal function can assume, make rigid chemical models for each of them if possible and compare their respective reactivity toward ozone.

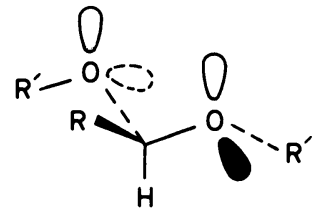

A

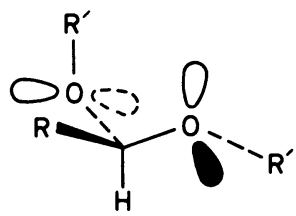

D

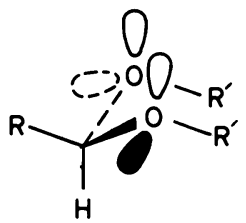

$\mathbf{F}$

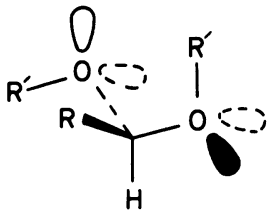

B

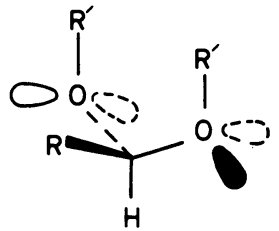

$E$

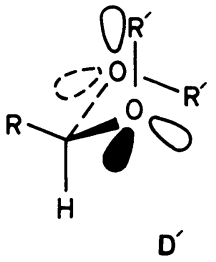

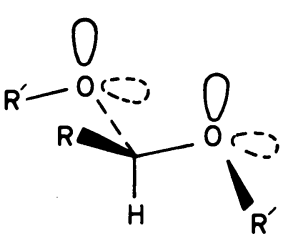

C

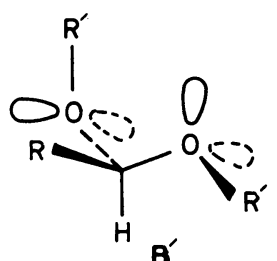

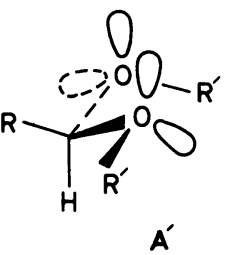

Figure 5.

Figure 5 shows the nine gauche conformers that are theoretically possible for an acetal function. Conformers A, B and $\mathbf{D}$ have no plane of symmetry. In fact, conformers $\mathbf{A}^{\prime}, \mathbf{B}^{\prime}$ and $\mathbf{D}^{\prime}$ are their respective mirror images, and therefore chemically equivalent. The remaining conformers $\mathbf{C}, \mathbf{E}$ and $\mathbf{F}$ possess a plane of symmetry. Consequently, there are only six conformers

$\dagger$ A 1,3-syn-periplanar arrangement is equivalent to a 1,3-diaxial arrangement in a sixmembered ring. 
for an acetal function (A, B, C, D, E and F) which are chemically different. Of those, only conformers $\mathbf{A}, \mathbf{C}$ and $\mathbf{F}$ possess a lone pair orbital on each oxygen oriented antiperiplanar to the $\mathbf{C}-\mathrm{H}$ bond. Conformers $\mathbf{B}$ and $\mathbf{D}$ have only one oxygen with a lone pair properly oriented, and conformer $\mathbf{E}$ has none. Consequently, if the above postulate is valid, conformers $\mathbf{B}, \mathbf{D}$ and $\mathbf{E}$ should be inert and conformers $\mathbf{A}, \mathbf{C}$ and $\mathbf{F}$ should be reactive. The reactivity of a variety of acetal substrates toward ozone was therefore undertaken and the experimental results which have been published earlier ${ }^{2}$, confirmed that the preceding postulate was indeed valid. Consequently, there is a direct relationship between the orientation of the lone pair orbitals relative to the $\mathrm{C}-\mathrm{H}$ bond and the reactivity of the acetal function toward ozone oxidation.

We have also postulated that the oxidation of acetals proceeds via the formation of a hemi-orthoester intermediate. If this postulate is also correct, it is possible that the orientation of the lone pair orbitals might also play an important role in the cleavage of such a hemi-orthoester. Indeed, the specific formation of hydroxy-ester 5, instead of lactone 6, in the ozonolysis of tetrahydropyranyl ether 3 can be easily explained by the application of a new simple stereoelectronic rule on the postulated hemi-orthoester intermediate 4.

\section{STEREOELECTRONIC CONTROL IN THE CLEAVAGE OF HEMI-ORTHOESTERS}

A hemi-orthoester intermediate such as $\mathbf{1 1}$ (Figure 6) can be cleaved to yield two different esters, 12 and 13, each of which can have a trans $(\mathbf{E})$ or a cis $(\mathrm{Z})$ conformation ${ }^{7,8}$. Thus, 11 can lead, in principle, to four products: 12A, 12B, 13A or 13B. Theoretically, there are nine different gauche conformers for a tetrahedral intermediate such as 11 (Figure 7). We want to propose a new stereoelectronic theory which predicts the manner by which each tetrahedral conformer can cleave.

The stereoelectronic theory is very simple: The precise conformation of the tetrahedral intermediate is transposed into the product of the reaction and a cleavage of a $\mathrm{C}-\mathrm{O}$ alkyl bond is allowed only if the other two oxygens of this intermediate each have an orbital oriented antiperiplanar to the $\mathrm{C}-\mathrm{O}$ alkyl bond to be broken. We will examine in detail the stereoelectronically controlled cleavage of conformers $\mathbf{A}, \mathbf{B}$ and $\mathbf{C}$ as examples.

Conformer A (Figure 8) is allowed to break down in only one direction yielding the $\mathbf{E}$ ester 12A by ejecting the $\mathrm{OCH}_{3}$ group. The $\mathrm{C}-\mathrm{OCH}_{3}$ bond can be easily cleaved because the negative oxygen and the OR oxygen each have an orbital oriented antiperiplanar to this bond. The $\mathbf{R}^{\prime}-\mathrm{C}$ bond in conformer $\mathbf{A}$ is antiperiplanar to the $\mathbf{O}-\mathbf{R}$ bond, and this spatial arrangement will be transposed in the resulting ester. Thus, stereoelectronically controlled cleavage of $\mathbf{A}$ furnishes the $\mathbf{E}$ ester 12A. The negative oxygen has one orbital oriented antiperiplanar to the $\mathrm{C}-\mathrm{OR}$ bond, but the oxygen of the $\mathrm{OCH}_{3}$ group does not : it is the $\mathrm{CH}_{3}-\mathrm{O}$ bond which is antiperiplanar to the $\mathrm{C}-\mathrm{OR}$ bond. Consequently, the cleavage of the $\mathrm{C}-\mathrm{OR}$ bond in conformer $\mathrm{A}$ should be a higher energy process than the cleavage of the $\mathrm{C}-\mathrm{OCH}_{3}$ bond because the ejection of the OR group cannot be achieved with the assistance of a 
<smiles>[R]OC([R])=O</smiles>

$12 \mathrm{~A}$<smiles>[R]C(=O)OC</smiles>

$13 \mathrm{~A}$
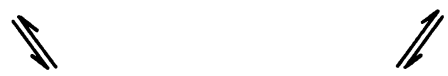<smiles>[R]C([O-])([O-])[O-]</smiles>

11
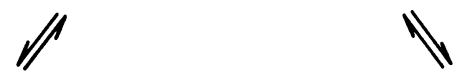

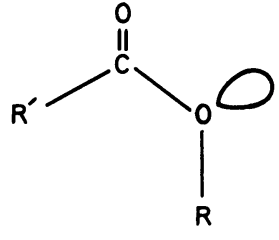

$12 \mathrm{~B}$<smiles>[R]C(=O)OC</smiles>

$13 \mathrm{~B}$

Figure 6.

lone pair orbital properly aligned on each of the two remaining oxygens. This process should therefore not be observed.

Conformer B like conformer A possesses proper orbital orientation and has a correct conformation to give the $\mathbf{E}$ ester 12A. In addition, it can be cleaved in a stereoelectronically controlled manner to give the $\mathbf{Z}$ ester 13B, because conformer $\mathbf{B}$ has one orbital on the negative oxygen and one on the oxygen of the $\mathrm{OCH}_{3}$ group properly aligned to permit the ejection of the OR group. The $\mathbf{R}^{\prime}$ group in $\mathbf{B}$ is in a gauche orientation with respect to the $\mathrm{CH}_{3}$ group, so, the $\mathbf{Z}$ ester 13B should be obtained. Thus, conformer $\mathbf{B}$ has proper orbital orientation and conformation to give either the $\mathbf{E}$ ester $12 \mathrm{~A}$ or the $\mathbf{Z}$ ester 13B.

Conformer $\mathbf{C}$, like conformers $\mathbf{A}$ and $\mathbf{B}$, also has proper conformation and orbital orientation to give the $\mathbf{E}$ ester $12 \mathrm{~A}$. It can also give the $\mathbf{E}$ ester $13 \mathbf{A}$, since the negative oxygen and the oxygen of the $\mathrm{OCH}_{3}$ group each have an 
PIERRE DESLONGCHAMPS
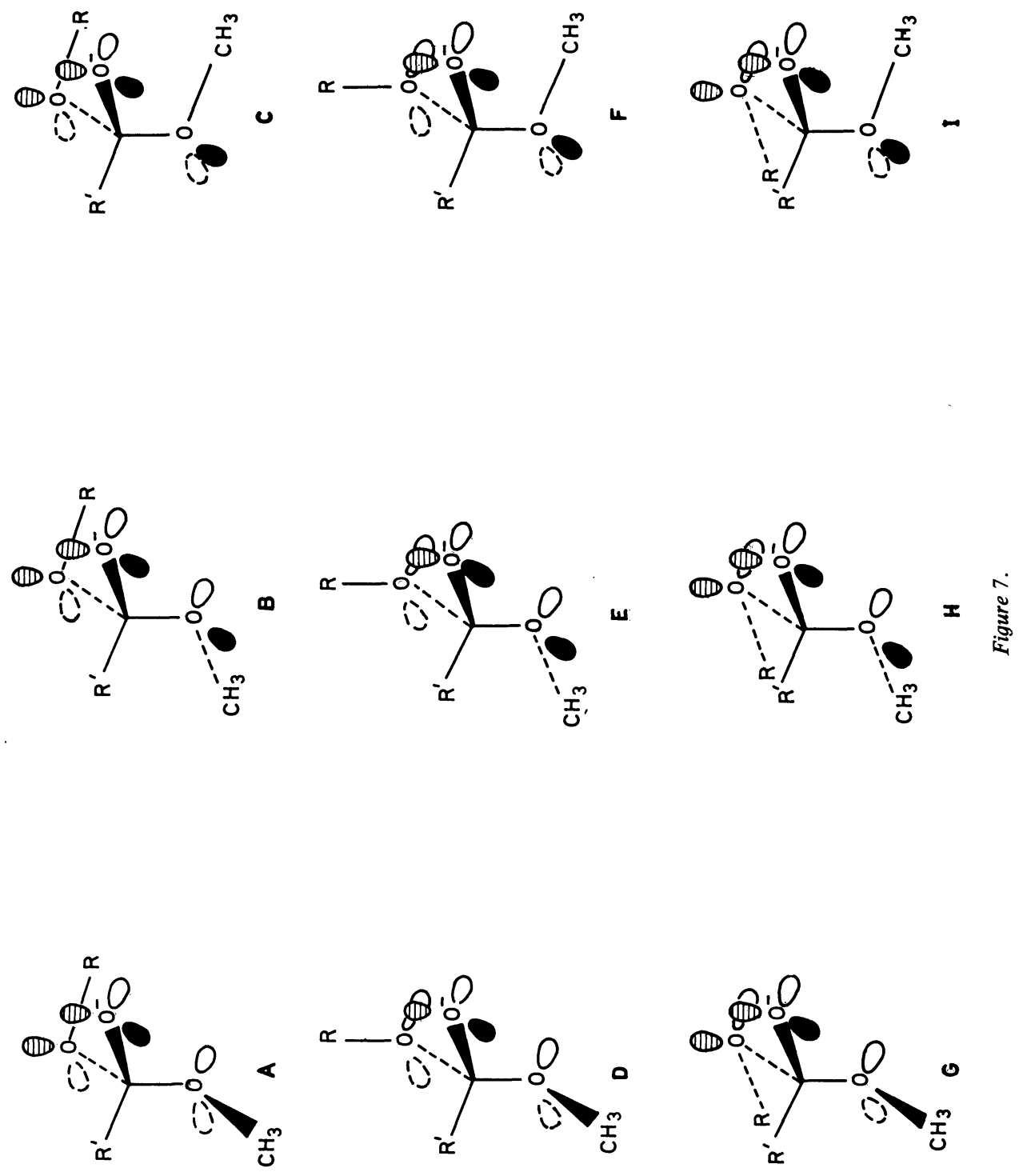
HYDROLYSIS OF ESTERS AND AMIDES
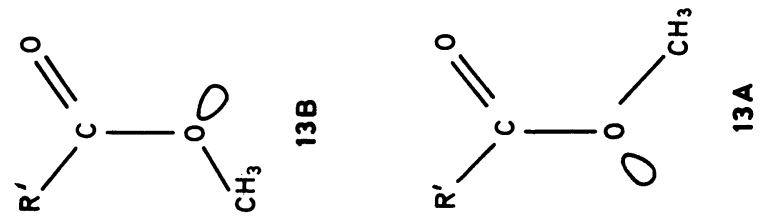

\#

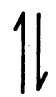

11
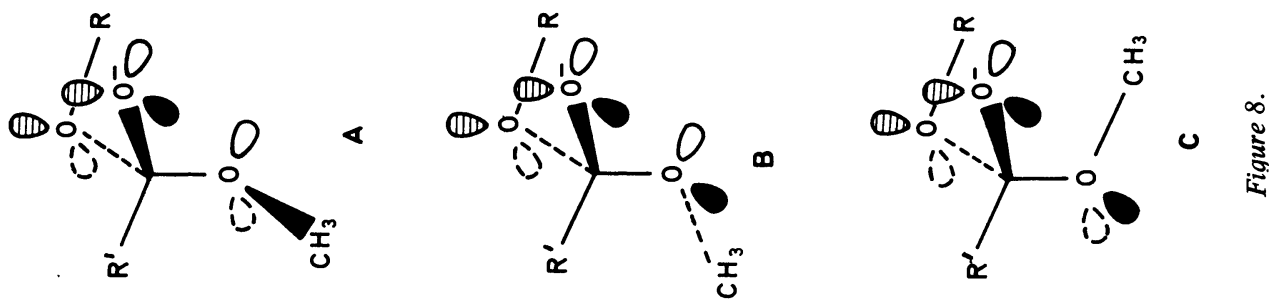

s

ij

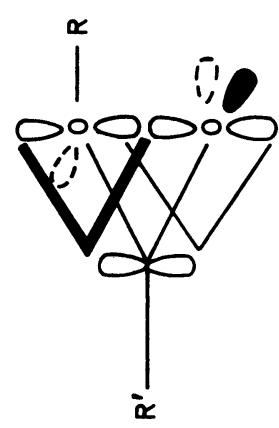

$\pm$ 
orbital antiperiplanar to the $\mathrm{C}-\mathrm{OR}$ bond, and the conformation of $\mathrm{C}$ is such that the $\mathrm{R}^{\prime}-\mathrm{C}$ bond is antiperiplanar to the $\mathrm{O}-\mathrm{CH}_{3}$ bond. Thus, $\mathrm{C}$ can either give $\mathbf{E}$ esters $12 \mathrm{~A}$ or $13 \mathrm{~A}$ via stereoelectronic control. Table 1 describes the stereoelectronic cleavages that are theoretically possible for the nine different gauche conformers of hemi-orthoester 11.

Table 1

\begin{tabular}{|c|c|c|c|c|}
\hline Ester 12 & & Conformer & & Ester 13 \\
\hline $\mathbf{E}$ & $\rightleftharpoons$ & $\mathbf{A}$ & 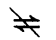 & \\
\hline $\mathbf{E}$ & $\rightleftharpoons$ & B & $\rightleftharpoons$ & $\mathbf{Z}$ \\
\hline $\mathbf{E}$ & $\rightleftharpoons$ & $\mathrm{C}$ & $\rightleftharpoons$ & $\overline{\mathbf{E}}$ \\
\hline & $\rightleftharpoons$ & $\mathbf{D}^{a}$ & $\rightleftharpoons$ & \\
\hline & $\rightleftharpoons$ & $\mathbf{E}$ & $\stackrel{\prime}{\rightleftharpoons}$ & $\mathbf{Z}$ \\
\hline & $\risingdotseq$ & $\mathbf{F}$ & $\rightleftharpoons$ & $\mathbf{E}$ \\
\hline $\mathbf{Z}$ & 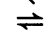 & $\mathbf{G}$ & $\rightleftharpoons$ & \\
\hline $\mathbf{Z}$ & $\rightleftharpoons$ & $\mathbf{H}$ & $\rightleftharpoons$ & $\mathbf{Z}$ \\
\hline $\mathbf{Z}$ & $\rightleftharpoons$ & I & $\rightleftharpoons$ & $\overline{\mathbf{E}}$ \\
\hline
\end{tabular}

a If a rigid conformer such as $\mathbf{D}$ is produced, it should cleave but the transition state will be of higher energy. Ozonolysis of trans-1,8-dioxaoctahydronaphthalene gives an intermediate equivalent to $\mathbf{D}^{2}$.

According to the principle of microscopic reversibility, the generation of a hemi-orthoester via alkoxide ion attack on an ester should also occur with stereoelectronic control.

Thus, when methoxide ion reacts with 12A for example, it can either give conformer A, B or C. These conformers are the result of methoxide ion attack perpendicular to the plane of the ester 12A. The $\mathbf{E}$ conformation of the starting ester 12A is thus transposed into the intermediate and, since methoxide ion can introduce itself in three different orientations, the three hemiorthoester conformers $\mathbf{A}, \mathbf{B}$ and $\mathbf{C}$ are theoretically possible.

The products formed in the ozonolysis reaction can now be easily explained. A tetrahydropyranyl ether reacts with ozone (Figure 9) through its most stable rotamer 14, giving specifically the tetrahedral intermediate 15 . This intermediate has proper orbital orientation to break the ring oxygen-carbon bond, thus forming the hydroxy-ester 5. Loss of the OR group to generate the $\delta$-lactone 6 is not possible through an orbital assisted mechanism simply because the lone pair orbitals of the ring oxygen are not properly aligned. It is the $\mathrm{C}_{6}-\mathrm{O}$ bond of the ring oxygen which is antiperiplanar to the OR group. The intermediate $\mathbf{1 5}$ is an example of conformer $\mathbf{A}$ in Figure 8.

This explanation is of course valid only if the ozonolysis reaction really occurs through the formation of a hemi-orthoester intermediate. It is, however, experimentally difficult to demonstrate that a hemi-orthoester is formed in the course of this reaction. Consequently, the results obtained from the ozonolysis reaction could be utilized to propose the new stereoelectronic theory but not to verify it. It was necessary to devise an experimental method to confirm that specific cleavage of hemi-orthoesters does indeed take place. The study of the acid hydrolysis of orthoesters was undertaken for that purpose. 


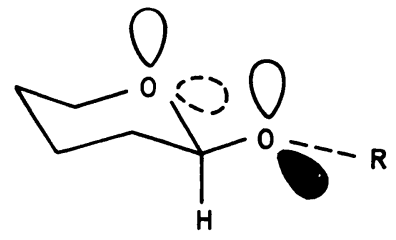

16

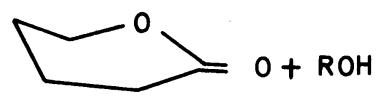

6

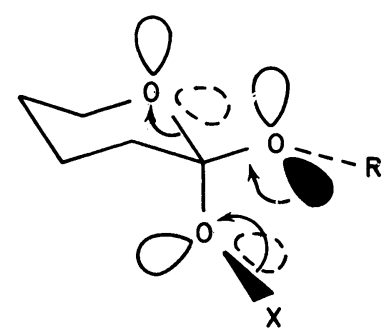

15
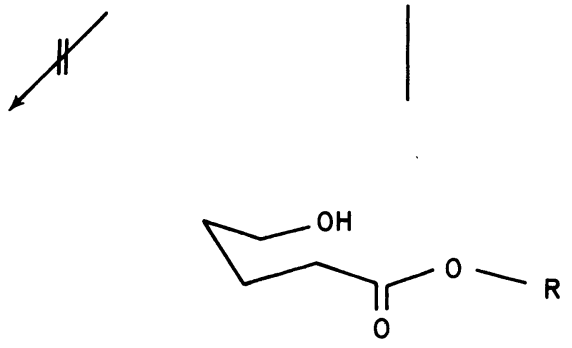

5

( $R$ = ethyl)

Figure 9.

\section{HYDROLYSIS OF CYCLIC MIXED ORTHOESTERS}

The formation of esters from the mild acid hydrolysis of orthoesters doubtless proceeds through the formation of a hemi-orthoester intermediate as described in the following equation ${ }^{9}$.<smiles>[R20]O[R20]([R20])([R20])[R]</smiles>

Accordingly, the preparation and the hydrolysis of the cyclic orthoesters shown in Figure 10 was undertaken ${ }^{3,10}$. The formation of products from the mild acid hydrolysis of these orthoesters was followed by carbon- 13 nuclear magnetic resonance spectroscopy. After ten minutes at room temperature, the hydrolysis of the orthoesters was completed and the corresponding hydroxy-esters were formed exclusively. No lactone products were detected. These results constitute rigorous experimental evidence that hemi-orthoesters do indeed break down in a specific manner, and can therefore be used to support the stereoelectronic theory.

In order to use the stereoelectronic theory to explain the exclusive formation of hydroxy-ester from the mild acid hydrolysis of orthoesters, we will 
<smiles>CCOC1(OCC)CCCCO1</smiles>

16<smiles>CCOC1(OCC)CCCC(C)O1</smiles><smiles>CCOC1(OCC)CC(C(C)C)CCO1</smiles><smiles>CCOC1(OCC)CC2CCCCC2CO1</smiles><smiles>CCOC1(OCC)CCCO1</smiles><smiles>CCOC(=O)CCCCO</smiles>

5<smiles>CCOC(=O)CCCC(C)O</smiles><smiles>CCOC(=O)CC(CCO)C(C)C</smiles><smiles>CC(C)C1CCOC(=O)C1</smiles><smiles>CCOC(=O)CC1CCCCC1CO</smiles><smiles>O=C1CC2CCCCC2CO1</smiles><smiles>CCOC(=O)CCCO</smiles><smiles>O=C1CCCO1</smiles>

Figure 10.

have to discuss the stereoelectronically controlled cleavage of precise conformations of hemi-orthoesters. We must consider all the possible conformations that an orthoester can assume, so that all the possible hemi-orthoester conformers are being considered. The simple six-membered cyclic orthoester 16 is a good example because it is preferable to discuss precise conformation in a six rather than in a five-membered ring. Also, we can assume that no conformational change takes place during the hydrolysis, since the experimental results are the same for both rigid and conformationally labile cyclic orthoesters.

There are nine gauche conformers which are theoretically possible for the cyclic orthoester 16. They are described in Figure 11. The next task is to define which conformers of $\mathbf{1 6}$ should be taken into consideration. It is logical to assume that the hydrolysis of 16 will proceed through the most energetically favoured conformers. These conformers should also have proper orbital orientation to permit the cleavage of a carbon-oxygen bond. A detailed examination of each conformer shows that six of them (B, C, D, G, H and I) are readily eliminated. 
HYDROLYSIS OF ESTERS AND AMIDES
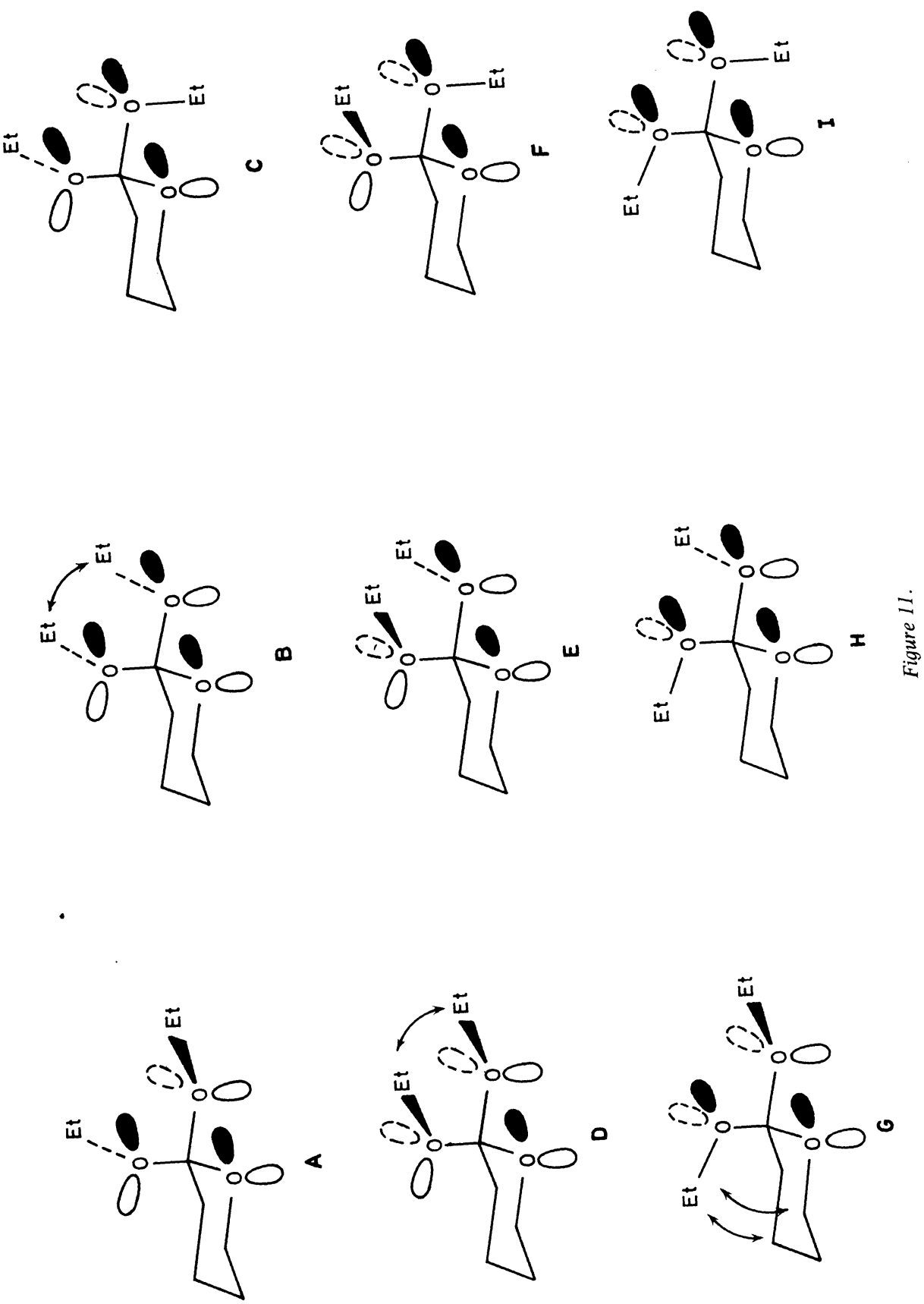

363 


\section{PIERRE DESLONGCHAMPS}

The population of conformers $\mathbf{B}$ and $\mathbf{D}$ at equilibrium will be very small, since there is a severe 1,3-syn-periplanar interaction between the two ethyl groups. Conformers G, H and I can also be ruled out by utilizing a similar argument; the ethyl group of the axial ethoxy group in each conformer is in a 1,3-syn-periplanar arrangement with two methylenes $\left(\mathrm{C}_{3}\right.$ and $\left.\mathrm{C}_{5}\right)$ of the ring. Due to this severe steric interaction, the population of these conformers will be very small at equilibrium. They can therefore be neglected.

The remaining four conformers $\mathbf{A}, \mathbf{C}, \mathbf{E}$ and $\mathbf{F}$ do not have strong steric interaction. The magnitude of the anomeric effect ${ }^{5}$, which occurs whenever two lone pair orbitals are in a 1,3-syn-periplanar arrangement is approximately the same in each conformer. Two of such orbital arrangements are present in conformers $\mathbf{A}, \mathbf{E}$ and $\mathbf{F}$. Conformer $\mathbf{C}$ has three. Thus, these four must represent the most important conformers of $\mathbf{1 6}$. However, $\mathbf{C}$ can be eliminated as a reactive conformer simply because it does not have proper orbital orientation on two oxygen atoms to permit the cleavage of the $\mathrm{C}-\mathrm{O}$ bond of the third oxygen atom. The remaining conformers $\mathbf{A}, \mathbf{E}$ and $\mathbf{F}$ have such an orbital orientation, and they will be considered separately.

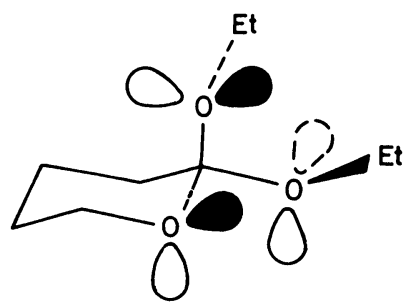

A

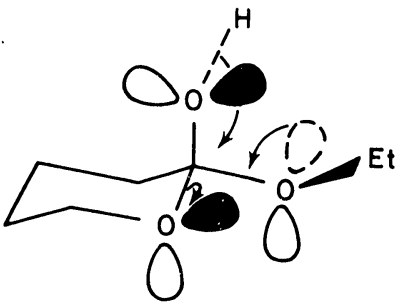

18

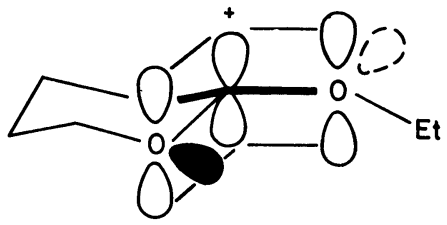

17

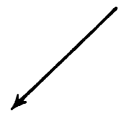<smiles>CCOC(=O)CCCCO</smiles>

5

Figure 12.

The cleavage of conformer A (Figure 12) can only give the dioxolenium ion 17 because of the orbital orientation. Ion 17 will then be attacked by water at the $\beta$ face to form specifically the hemi-orthoester 18 , in which the ring 
oxygen and the $\mathrm{OEt}$ oxygen each have an orbital antiperiplanar to the $\mathrm{C}-\mathrm{OH}$ bond which has just been formed. Attack of water at the $\alpha$ face of ion 17 would result in a hemi-orthoester with a ring in a boat form, and presumably this process can be ruled out. The hemi-orthoester 18 can break down in the direction of the hydroxy-ester 5 only; the $\mathrm{OH}$ and the OEt groups each have an orbital oriented antiperiplanar to the ring oxygen- $\mathrm{C}_{2}$ bond. The conversion of 18 into $\delta$-valerolactone (2) is a higher energy process, and therefore not observed, because the ring oxygen atom does not have proper orbital orientation to assist the cleavage of the $\mathrm{C}-\mathrm{CEt}$ bond.

Like conformer A, conformer F (Figure 13) should also yield the hydroxyester 5 exclusively, since orbital orientation permits only the cleavage of the ring oxygen-carbon bond. This process gives the dioxolenium ion 19. Hydration of ion 19 can be "accomplished in two ways, giving the hemiorthoesters 20 and 21. Both hemi-orthoesters 20 and 21 can then break down to give only the hydroxyester 5 .

Conformer E (Figure 14) has proper orbital orientation to permit the cleavage of the axial ethoxy group. The ion 22 thus formed will then hydrate to give the hemi-orthoester 23. The hemi-orthoester 23 does not have proper orbital orientation to permit the cleavage of a carbon-oxygen bond. In order to break down, 23 will have to convert to a reactive conformer by rotating one of its $\mathrm{C}-\mathrm{O}$ bonds $\dagger$. For example, a rotation of the $\mathrm{C}-\mathrm{OEt}$ bond will give 18 which will break down to give the hydroxy-ester 5 . A chair inversion of 23 to form 24 is also possible in a conformationally labile system; this new intermediate 24 should give $\delta$-valerolactone (6). Thus, lactone formation could have been observed to some extent via conformer $\mathbf{E}$, if the orthoester is a conformationally labile system.

The preceding discussion on the manner by which conformers $\mathbf{A}, \mathbf{E}$ and $\mathbf{F}$ should break down indicates that each of them is, in principle, a reactive conformer. If the relative stability of the dioxolenium ions is taken into consideration, we believe conformer $\mathbf{E}$ can be eliminated. Conformers A, E and $\mathbf{F}$ form the dioxolenium ions 17, 22 and 19 respectively (Figure 15). The ions 17 and 19 are trans $(\mathbf{E})$ and the ion 22 is cis $(\mathbf{Z})$. It is known that $\mathbf{E}$ dioxolenium ions are more stable than $\mathbf{Z}$ dioxolenium ions ${ }^{11}$, just as $\mathbf{E}$ esters are more stable $Z$ esters $^{6}$. If this difference in stability between 17,19 and 22 is also operative in the transition states which are going to form those dioxolenium ions, the cleavage of conformer $\mathbf{E}(\rightarrow 22)$ should be a higher energy process. Conformer $\mathbf{E}$ could thus be eliminated on that basis.

It is more difficult to find arguments to differentiate between conformer $\mathbf{A}$ and conformer F. However, the formation of the ion $\mathbf{1 7}$ from $\mathbf{A}$ should be an easier operation than formation of 19 from $F$. In principle, the formation of a cyclic dioxolenium ion (17) should be favoured over an acyclic dioxolenium ion (19) when the starting orthoester is cyclic. Cleavage of conformer $\mathbf{A}$ gives two molecules, the cyclic ion $\mathbf{1 7}$ and ethanol. Conformer $\mathbf{F}$ gives only one molecule, the ion 19. This entropy factor should favour conformer A over conformer $\mathbf{F}$ as the reactive species.

$\dagger$ We have previously postulated ${ }^{3}$ that a tetrahedral intermediate which does not have proper orbital orientation to break down, will prefer to undergo rotational changes to give new tetrahedral intermediates having orbitals properly aligned to undergo $\mathrm{C}-\mathrm{O}$ bond cleavage. 

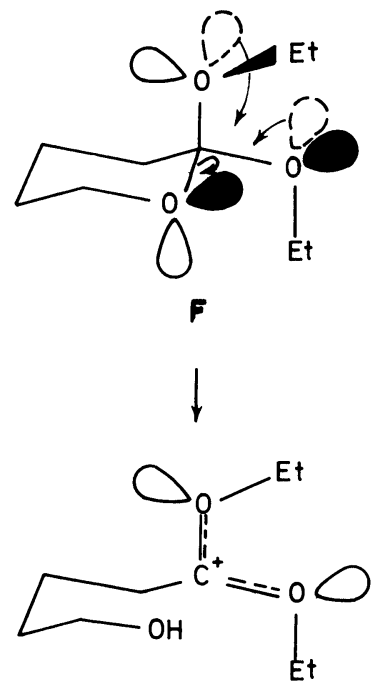

19

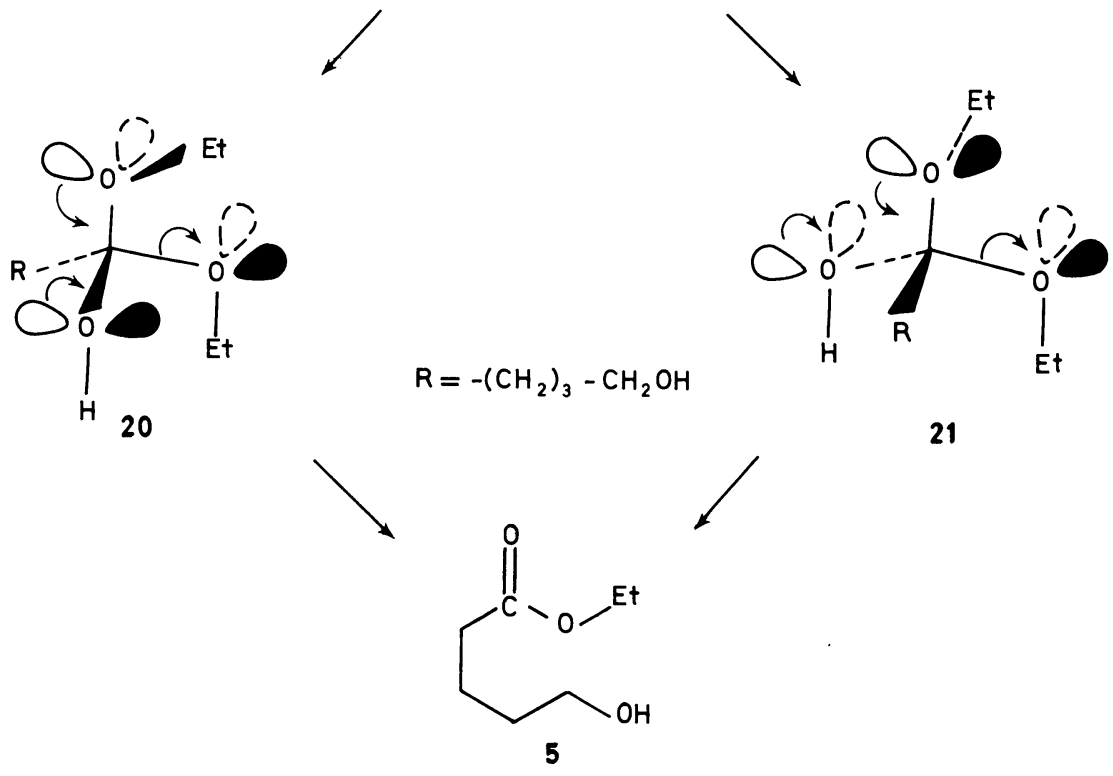

Figure 13

It is possible to devise a simple experiment to determine if conformer $\mathbf{F}$ is more reactive than conformer $\mathbf{A}$. If the stereoelectronic theory is applied, it is interesting to note that conformer $\mathbf{A}$ will give the hydroxy-ester $\mathbf{5}$ by the loss of its axial ethoxy group (Figure 12). It is also predicted that $\mathbf{F}$ will form 5 by ejecting its equatorial ethoxy group. Hydration of 19 can give either 


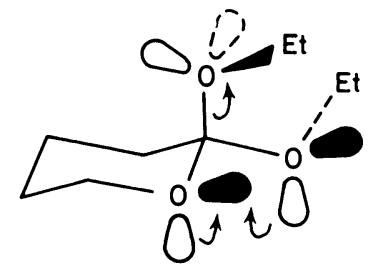

E

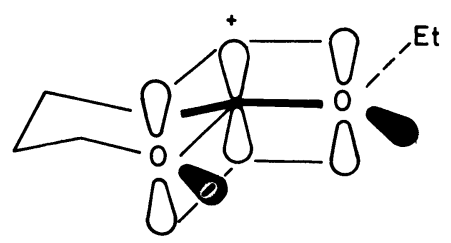

22

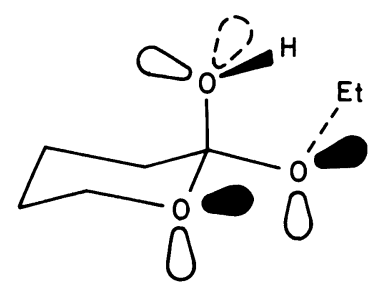

23
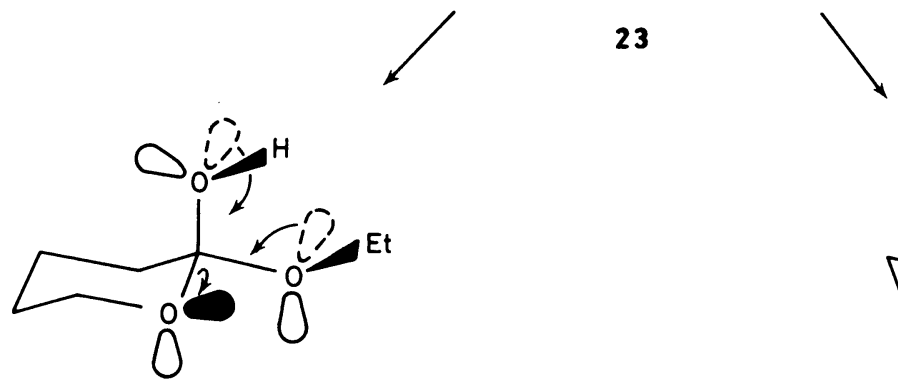<smiles>CCOC(=O)CCCCO</smiles>

5
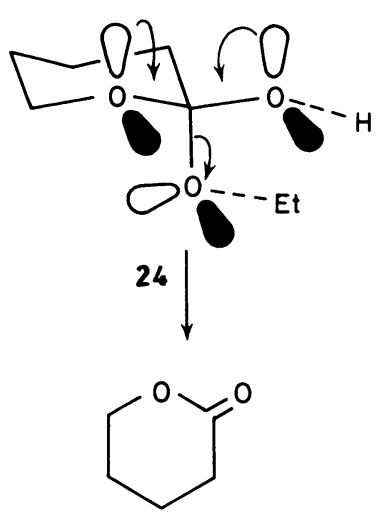

6

Figure 14

20 or 21 which will break down by ejecting the same ethoxy group, the equatorial one of conformer F. Figure 13 describes this operation. Thus, if the preparation of rigid cyclic orthoesters having two different alkoxy groups can be realized, it should be easy to differentiate between these two pathways.

We have already developed a method for the synthesis of conformationally rigid cyclic orthoesters. For instance, lactone 25 was converted into lactonium salt 26 by reaction with triethyloxonium tetrafluoroborate. Reaction of $\mathbf{2 6}$ with sodium ethoxide gave the cyclic orthoester 27 (Figure 16). This successful 


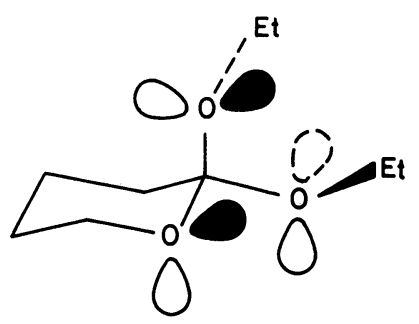

A<smiles>[3H][3H]</smiles><smiles>CCOC1(OCC)CCCCO1</smiles>

17<smiles>O=C1CC2CCCCC2CO1</smiles>

25

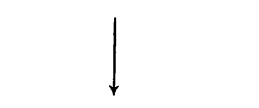<smiles>CC[O+]=C1CC2CCCCC2CO1</smiles>

26

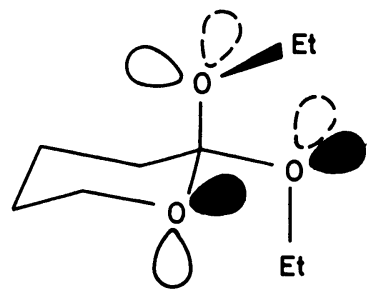

$\mathbf{F}$<smiles>[3H][3H]</smiles><smiles>[R]C(=O)OCC</smiles>

19

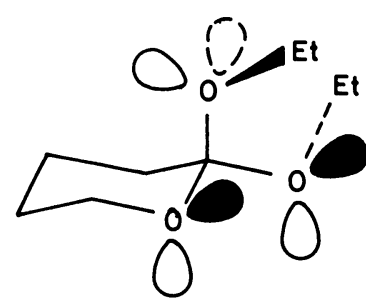

E

$$
\downarrow
$$

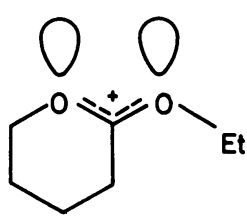

22

Figure 15<smiles>CCOC1(OCC)CC2CCCC[C@H](CO1)C2</smiles><smiles>CCOC(=O)CC1CCCCC1COC(C)=O</smiles><smiles>CCOC1(OCC)CC2CCCCC2CO1</smiles>

29

Figure 16

synthesis of a rigid cyclic orthoester by sequential introduction of the alkoxy groups was ideal for the synthesis of mixed orthoesters, if the last step is stereospecific. The addition of alkoxide ion to a rigid lactonium salt like 26 should indeed be completely stereospecific if the stereoelectronic theory is valid. 
<smiles>O=C1CC2CCCCC2CO1</smiles>

25<smiles>COC1(OC)C[C@H]2CCCC[C@H]2O1</smiles><smiles>C[O+]=C1CC2CCCCC2CO1</smiles>

30<smiles>CCOC1(OC)CC2CCCCC2CO1</smiles><smiles>CC(=O)CC1CCCCC1COC(C)=O</smiles><smiles>CI</smiles><smiles>COC1(C)CCC2CCCCC2CO1</smiles><smiles>CO[C@]1(C)C[C@H]2CCCC[C@H](C2)O1</smiles><smiles>CO[C@]1(C)C[C@H]2CCCC[C@H](C2)O1</smiles>

Figure 17

When 26 was treated with sodium methoxide in a mixture of methanol and $i$-propanol, the mixed orthoester 28 was obtained. None of the other possible mixed orthoester 32 was present $\dagger$ (Figure 17). The addition of sodium methoxide to $\mathbf{2 6}$ is thus completely stereospecific. The stereoelectronic rule permits the formation of the epimeric orthoester 32 from 26, but the attack of methoxide ion at the $\alpha$ face of the salt 26 will give 32 in a high energy conformation; the orthoester ring of 32 will be in a boat form. Thus, the $\alpha$ attack is much less favoured than the $\beta$ attack, since the latter process yields 28 directly in its more stable conformation.

The methyl lactonium salt 30 was prepared by reaction of lactone 25 with trimethyloxonium tetrafluoroborate (Figure 17). An authentic sample of the dimethoxy orthoester 31 was prepared by reacting 30 with sodium methoxide in methanol. The methyl lactonium salt $\mathbf{3 0}$ was also reacted with sodium

$\dagger$ In this reaction, a small quantity ( $\simeq 3 \%$ ) of the dimethoxy orthoester 31 is formed by a competitive secondary process. When the salt $\mathbf{2 6}$ was reacted with sodium methoxide in pure methanol, this secondary process became the major one, 31 was formed in $60 \%$ and 28 in $40 \%$ yield. 
ethoxide in ethanol to give the mixed orthoester 32†. The lactonium salt 30 was also reacted with deuterated sodium methoxide and the mixed cyclic orthoester 34 was obtained specifically $\ddagger$; none of the isomeric orthoester 35 was formed§.

The orthoesters 28, 32 and 34 were hydrolysed with water containing $p$-toluenesulphonic acid. The reaction mixture was then treated with pyridine and acetic anhydride and the resulting acetoxy esters were analysed by n.m.r. spectroscopy and vapour phase chromatography. Compound 28 (containing $\simeq 3 \%$ of 31) gave the acetoxy ethyl ester 29 containing a small quantity of 33 $(\simeq 3 \%)$. Compound 32 (containing $\simeq 8 \%$ of 27 ) gave the acetoxy methyl ester 33, containing a small quantity of $29(\simeq 8 \%)$. Finally, the hydrolysis of 34 (containing $12 \%$ of 36 ) gave the acetoxymethyl ester 33 along with a small quantity of the deuterated acetoxy methyl ester $\left(33, \mathrm{OCH}_{3}=\mathrm{OCD}_{3}\right)$.

The above results show that the hydrolysis of cyclic orthoesters proceeds by loss of the axial alkoxy group. Consequently conformer $\mathbf{F}$ can be eliminated as a reactive conformer, and the hydrolysis of cyclic dialkoxy orthoesters must take place through conformer A via stereoelectronic control.

We would like to point out that the successful stereospecific synthesis of mixed cyclic orthoesters constitutes rigorous evidence for the direction of attack of the alkoxide on the cyclic dioxolenium ions. Also, the stereospecificity observed in the hydrolysis of these mixed cyclic orthoesters demonstrates that this reaction proceeds according to the same principle in the opposite direction.

\section{STEREOELECTRONIC CONTROL IN THE CLEAVAGE OF HEMI-ORTHOAMIDES}

A hemi-orthoamide such as $\mathbf{3 8}$ (Figure 18) can, in principle, break down to give either the amide-alcohol products or the ester-amine products. The theory of stereoelectronic control in the cleavage of a hemi-orthoamide can be verified if a method can be found to produce such an intermediate in an irreversible and specific manner. Also, this method should provide some knowledge about the conformation of 38. Then, if a logical correlation between the conformation of $\mathbf{3 8}$ and the formation of products resulting from its breakdown can be obtained, it will constitute experimental evidence to support the theory of stereoelectronic control.

It is not possible to produce a hemi-orthoamide such as $\mathbf{3 8}$ in a mild and irreversible fashion by treating an amide with an alkoxide ion. Similarly, 38 cannot be obtained by treating an ester with an amide anion. However, an ideal precursor appeared to be an $N, N$-dialkylated imidate salt (37), which can be considered to be an activated amide. Indeed, it is known that imidate salts are rapidly hydrolysed under basic conditions ${ }^{12}$, at room temperature,

\footnotetext{
$\dagger$ Diethoxy orthoester 27 was formed to the extent of $\simeq 8 \%$ in this reaction.

$\ddagger$ Mass spectral analysis indicated the presence of $\simeq 12 \%$ of the completely deuterated orthoester 36 along with 34 . Analysis by carbon-13 nuclear magnetic resonance indicated $13 \%$ of 36 .

$\S$ The stereochemistry of the mixed cyclic orthoesters 28,32 and 34 was established by proton nuclear magnetic resonance spectroscopy with the aid of compounds 27 and 31 as models. The axial alkoxy group has a higher chemical shift than the equatorial alkoxy group $(\Delta \delta=0.10$ p.p.m.).
} 


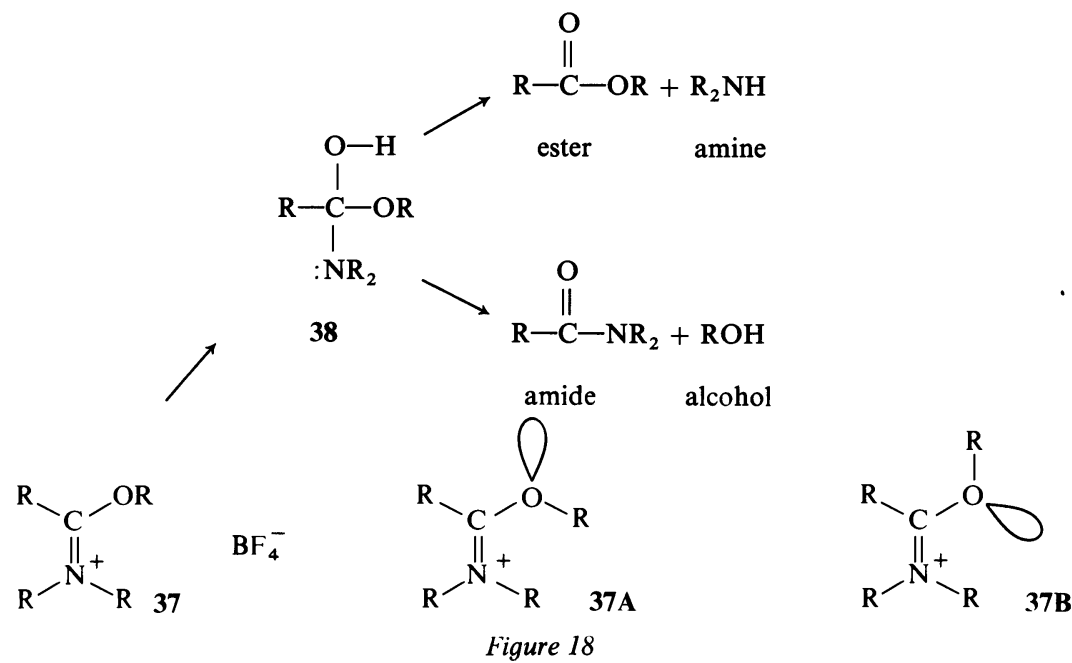

to give ester and amine or amide and alcohol as products. When a fluoroborate imidate salt such as $\mathbf{3 7}$ reacts with sodium hydroxide, it forms sodium fluoroborate and the intermediate 38 which rapidly breaks down in an irreversible manner to the products of the reaction $\dagger$. It is experimentally very difficult to know the precise conformation of a hemi-orthoamide such as 38 . However, the conformation of $\mathbf{3 8}$ can be obtained indirectly by the utilization of the new stereoelectronic theory and the knowledge of the precise conformation of the starting imidate salt 37 . Thus, the conformation of imidate salts must first be taken into consideration.

We believe that imidate salts are planar and thus can exist in two different conformations, the $\mathbf{E}$ (37A) or the $\mathbf{Z}$ (37B) form. In the $\mathbf{E}$ conformation $37 \mathrm{~A}$, the $\mathrm{O}-\mathrm{R}$ bond is antiperiplanar to the $\mathrm{C}-\mathrm{R}$ bond. In the $\mathrm{Z}$ conformation 37B, the $\mathrm{O}-\mathrm{R}$ bond is syn to the $\mathrm{C}-\mathrm{R}$ bond. Application of the new stereoelectronic theory on each type of imidate salt leads to the following predictions concerning the precise conformation of the intermediate $\mathbf{3 8}$ and the manner by which each conformer of $\mathbf{3 8}$ should then break down.

According to this theory, the reaction of hydroxide ion with the $\mathbf{E}$ form 37A of an imidate salt should give the tetrahedral conformer 38A specifically (Figure 19). Conformer 38A is the result of hydroxide ion attack perpendicular to the plane of the salt 37A. The conformation of the starting imidate

+ If ester and amine are obtained as products, it is clear that it is the result of kinetically controlled cleavage of $\mathbf{3 8}$ and will indicate that the transition state leading to those products is of lower energy than the one leading to the more stable amide and alcohol products. Under equilibrating conditions, the amide and alcohol products will always completely predominate over the ester and amine products. However, it is possible that in some cases, the amide and alcohol are also the kinetic products of the cleavage of the intermediate 38. In such a circumstance, it is in principle possible to use the result as evidence for the new stereoelectronic theory, if it can be clearly established that the reaction is kinetically controlled. For instance, if the corresponding ester and amine are not converted into the amide and alcohol products under the experimental conditions used for the hydrolysis of the imidate salt, it demonstrates that the formation of amide and alcohol from the hydrolysis of such imidate salts, is the result of kinetically controlled cleavage of the intermediate 38 . 
PIERRE DESLONGCHAMPS

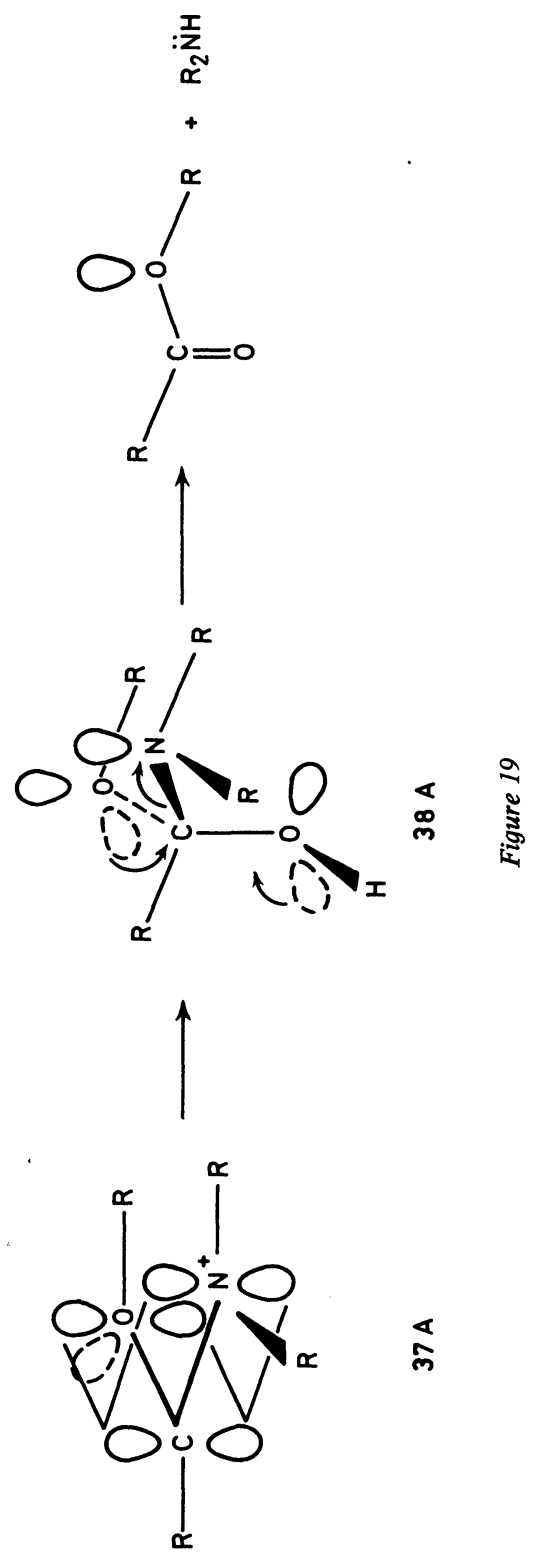


salt $37 \mathrm{~A}$ is thus transposed to the intermediate $38 \mathrm{~A}$; the $\mathrm{R}-\mathrm{C}$ bond in $38 \mathrm{~A}$ is antiperiplanar to the $\mathrm{O}-\mathrm{R}$ bond and to one of the $\mathrm{N}-\mathrm{R}$ bonds as in the $\mathbf{E}$ imidate $37 \mathrm{~A} \dagger$. As a consequence of the stereoelectronic theory, one of the lone pair orbitals of the oxygen of the OR group and the lone pair orbital of the nitrogen must be oriented antiperiplanar to the new carbon-oxygen bond. Thus, the reverse reaction, the ejection of the hydroxyl group can be achieved by an orbital assisted mechanism because there are two heteroatoms each having a lone pair orbital properly oriented antiperiplanar to the leaving group. The principle of microscopic reversibility is thus adhered to.

One more assumption has to be made to make the preceding theory valid. Whenever a tetrahedral intermediate possesses proper orbital orientation, its halflife is very short and it breaks down to products immediately. This implies that the energy barrier for conformational changes by rotation of $\mathrm{C}-\mathrm{N}$ and $\mathrm{C}-\mathrm{O}$ bonds in $\mathbf{3 8 \mathrm { A }}$ is higher than the energy barrier for its breakdown. With such a condition, no tetrahedral conformer other than 38A must be taken into consideration in the hydrolysis of $\mathbf{E}$ imidate salt 37A.

Examination of the orientation of the lone pair orbitals in 38A indicates that this conformer should break down to yield the ester and the amine only. The nitrogen orbital is not properly oriented to assist in expellling the OR group. At the same time, the two oxygens each have a lone pair orbital oriented antiperiplanar to the $\mathrm{C}-\mathrm{N}$ bond to permit a facile ejection of the amino group. Consequently, it is predicted that the basic hydrolysis of the $\mathbf{E}$ form 37A of an imidate salt should lead to the exclusive formation of ester and amine as a result of the cleavage of conformer 38A.

If the preceding stereoelectronic theory is valid, the reaction of hydroxide ion on the $\mathbf{Z}$ form 37B will give specifically the conformer 38B (Figure 20). Again 38B is the result of an attack perpendicular to the plane of the salt 37B by hydroxide ion. The conformation of 37B has also been retained in the intermediate 38B. There are lone pair orbitals on the nitrogen and on the oxygen of the OR group which are each oriented antiperiplanar to the $\mathrm{C}-\mathrm{OH}$ bond.

It is interesting to note that conformer 38B cannot break down to products by an orbital assisted mechanism; the nitrogen non-bonded orbital is not antiperiplanar to the C-OR bond. Similarly, the oxygen atom of the OR group does not have a non-bonded orbital properly oriented antiperiplanar to the $\mathrm{C}-\mathrm{N}$ bond. In this case, we postulate that the rotation of $\mathrm{C}-\mathrm{N}$ and $\mathrm{C}-\mathrm{O}$ bonds in conformer 38B becomes more facile than its breakdown to products and new conformers must be considered. If these new conformers have their orbitals properly oriented, they will break down immediately to give products. The energy barrier for carbon-nitrogen rotation should be of the same order of magnitude as the one for carbon-oxygen rotation. Both types of rotation must therefore be taken into consideration.

$\dagger$ In principle, hydroxide ion attack on the imidate can either lead to conformer $38 \mathrm{~A}$ or to two other conformers which differ in the orientation of the $\mathrm{O}-\mathrm{H}$ bond. These three conformers can be interconverted by proton transfer. This interconversion occurs at a diffusion controlled rate $^{13}$. Since we assume that the breakdown of the tetrahedral intermediate is a slower process than proton transfer, the three conformers are equivalent as far as the theory is concerned. 
PIERRE DESLONGCHAMPS
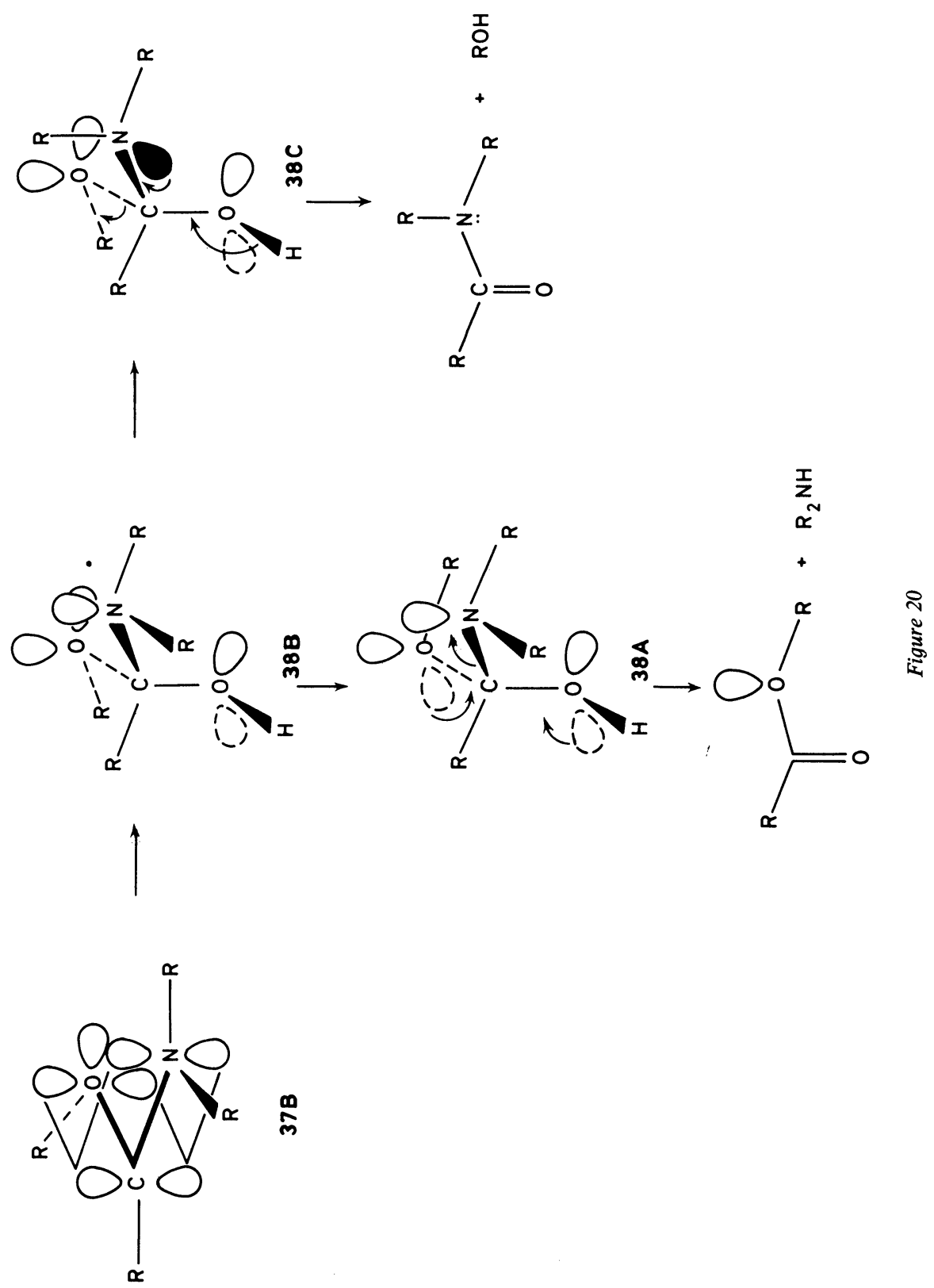
For example, by rotation of the carbon-nitrogen bond, conformer 38B can give a new conformer such as $\mathbf{3 8 C}$. In conformer 38C the hydroxyl oxygen and the nitrogen each have a lone pair orbital oriented antiperiplanar to the $\mathrm{C}-\mathrm{OR}$ bond. Intermediate $38 \mathrm{C}$ should thus immediately produce the amide and alcohol products. By rotation of the C-OR bond in 38B, a new conformer such as $38 \mathrm{~A}$ can also be obtained. We have already described that 38A should give the ester and amine products. Other conformers can be obtained by other rotations in 38B. The relative proportions of ester and amine products versus amide and alcohol products will thus depend on the new conformers that will be formed by bond rotation in conformer 38B. Consequently, it is predicted that the basic $\dagger$ hydrolysis of the $\mathbf{Z}$ form 37B of an imidate salt will give, in principle, mixtures of products.<smiles>C[N+]1=C(c2ccccc2)CCO1</smiles>

39

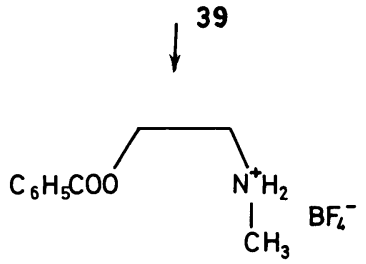

43

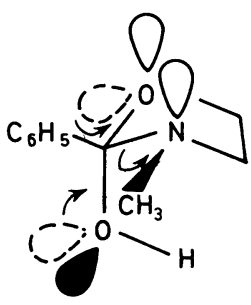

42
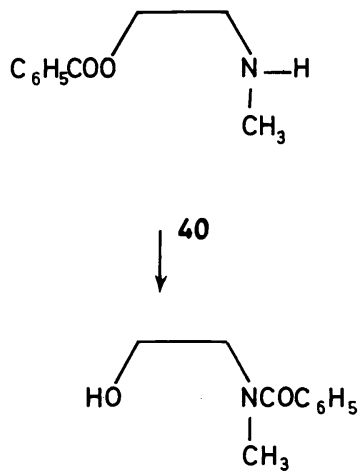

41

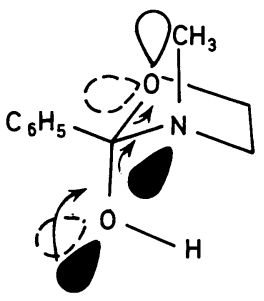

44

Figure 21

$\dagger$ It should be emphasized that this prediction is valid in a strong basic medium only. This condition is important because the protonation of the basic nitrogen of the tetrahedral intermediate effectively ties up its lone pair orbital. Thus, the nitrogen atom cannot participate in an orbital-assisted decomposition of the tetrahedral intermediate under acidic conditions. 


\section{HYDROLYSIS OF IMIDATE SALTS}

We will first describe the results obtained from the basic hydrolysis of imidate salts having an $\mathbf{E}$ conformation. The first substrate selected was the five-membered ring imidate salt $\mathbf{3 9}$ (Figure 2I) in which the $\mathbf{E}$ conformation is assured by the cyclic structure. Hydrolysis of $\mathbf{3 9}$ with four equivalents of sodium carbonate in a mixture of acetonitrile and water gave the benzoate amine 40 exclusively. The reaction was followed by proton n.m.r. spectroscopy and was complete after fifteen minutes at room temperature $\dagger$. If the reaction mixture was left at room temperature for a period of $24 \mathrm{~h}$, the benzoate amine 40 was completely converted into the more stable benzamide alcohol 41.

These experimental results can be easily explained by the stereoelectronic theory. The salt 39 forms the intermediate $\mathbf{4 2}$ in which the energy barrier to yield the ester-amine product $\mathbf{4 0}$ is lowered by the alignment of the orbitals on both oxygen atoms. It is possible that the experimental conditions used favour the reformation of tetrahedral intermediates by an attack of the amino group on the ester function of $\mathbf{4 0}$. Compound $\mathbf{4 0}$ can either reform $\mathbf{4 2}$ or form a new intermediate, such as $\mathbf{4 4}$, which has its orbitals properly aligned to yield the more stable product, the amide-alcohol 41. Consequently, the final result will be the exclusive formation of the thermodynamic product under equilibrating conditions. These conditions were obtained after a period of $24 \mathrm{~h}$ with sodium carbonate; they were immediately obtained when sodium hydroxide was utilized $\ddagger$.

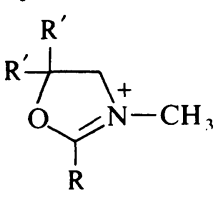

$45 \mathrm{R}=\mathrm{CH}_{3}, \mathrm{R}-\mathrm{H}$

$46 \mathrm{R}=\mathrm{C}_{6} \mathrm{H}_{5}, \mathrm{R}^{\prime}=\mathrm{CH}_{3}$<smiles>CCCCCCCC</smiles>

47<smiles>[R]C1([R])CC[N+](C)=C(CCCCC)O1</smiles>

$48 \mathrm{R}=\mathrm{H}$

$49 \mathrm{R}=\mathrm{CH}_{3}$

Figure 22

Hydrolysis of the imidate salts $45,46,47,48$ and 49 (Figure 22) was also carried out under a variety of basic conditions, and similar results were obtained. Under kinetically controlled conditions, these $\mathbf{E}$ imidate salts lead to the exclusive formation of ester-amine products as predicted by the stereoelectronic theory.

We have also undertaken the basic hydrolysis of the imidate salts $\mathbf{5 0}$ and 51 (Figure 23) which have a $\mathbf{Z}$ conformation by virtue of their cyclic structure.

$\dagger$ Compound $\mathbf{4 0}$ was isolated as the benzoate-acetamide derivative by treating the reaction mixture with an excess of pyridine and acetic anhydride; the benzoate-acetamide derivative was identified by comparison with an authentic sample.

$\ddagger$ The basic hydrolysis of 39 was also carried out with sodium hydroxide. Under such conditions, the imidate salt 39 gave directly the benzamide alcohol 41 ; the benzoate amine 40 was not detected. This result can be explained if the transformation of the benzoate amine $\mathbf{4 0}$ into the more stable benzamide alcohol $\mathbf{4 1}$ is very rapid in the presence of sodium hydroxide. This assertion was shown to be true in the following way. The benzoate ammonium salt 43 was prepared by the hydrolysis of 39 in neutral water. When the ammonium salt 43 was treated with sodium hydroxide under the conditions described for the hydrolysis of 39, it gave directly the benzamide alcohol 41. 

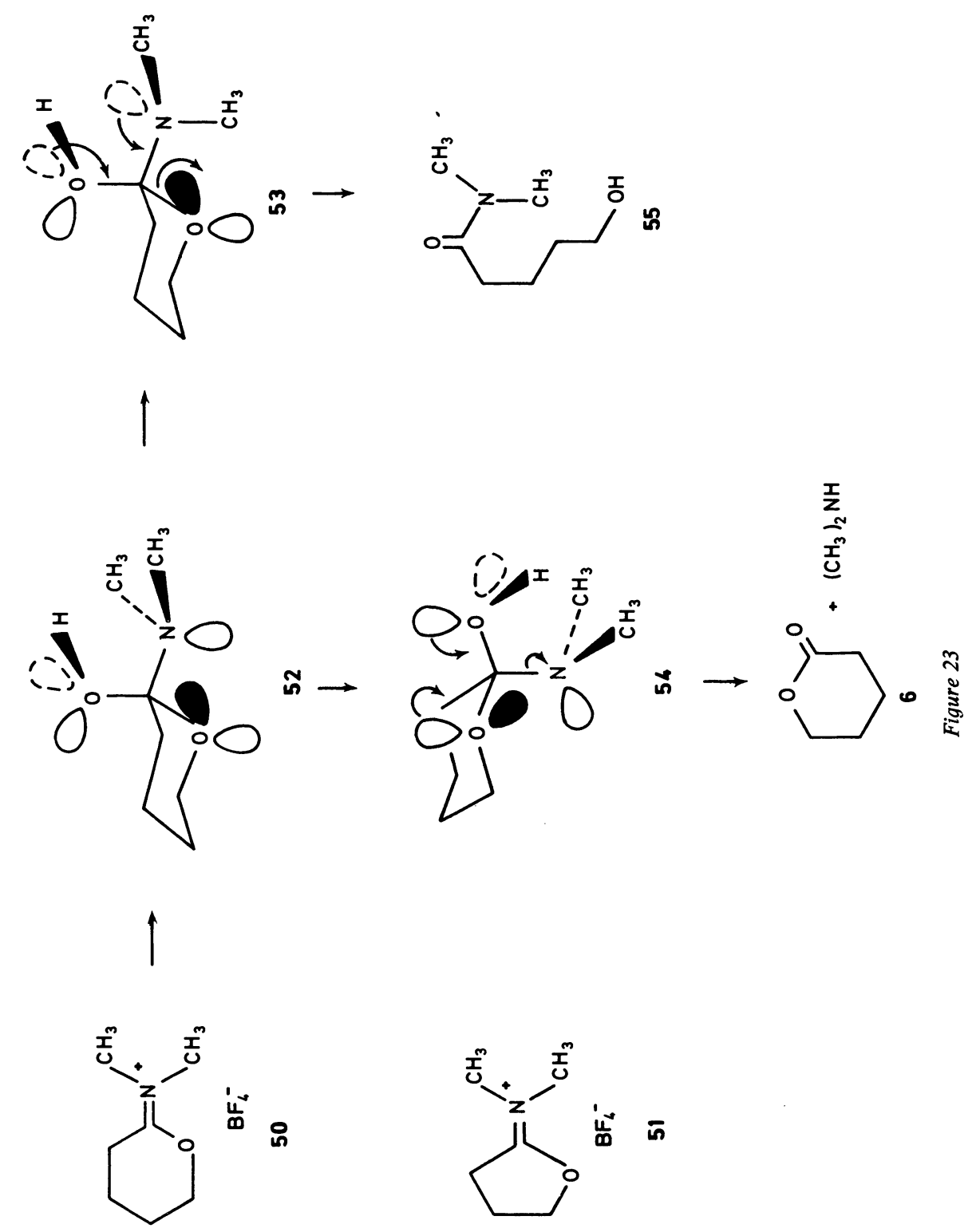
The hydrolysis of $\mathbf{5 0}$ should give the intermediate $\mathbf{5 2}$, which is equivalent to 38B. Thus, $\mathbf{5 2}$ cannot break down easily if the stereoelectronic theory is valid. However, intermediate 52 can undergo conformational changes to yield either 53 (by carbon-nitrogen rotation) or 54 (by chair inversion). Conformer 53 has its orbitals properly oriented to give the hydroxy-amide 55, while conformer 54 should yield $\delta$-lactone 6 and dimethyl amine. Thus, we should expect a mixture of products 6 and $\mathbf{5 5}$ from the basic hydrolysis of 50. The hydrolysis was carried out with sodium hydroxide in aqueous acetonitrile. Indeed, the imidate salt 50 gave a mixture of hydroxy amide $55(66 \%)$ and lactone $6(33 \%)$. Likewise, the hydrolysis of the imidate salt 51 gave a one to one mixture of the corresponding hydroxy amide and $\gamma$-butyrolactone.

We have described the hydrolysis of rigid $\mathbf{E}$ imidate salts. These compounds were predicted to give the ester-amine products exclusively and we have obtained experimental results to confirm this prediction. The hydrolysis of rigid $\mathbf{Z}$ imidate salts was predicted to give mixtures of ester-amine and amide-alcohol products under kinetically controlled conditions. Again, our experimental results support this prediction. Thus, there is certainly a relationship between the conformation of the tetrahedral intermediate and the nature of the products formed as a result of breakdown. It appears that orbital orientation is an important factor in lowering the energy barrier for the breakdown of such a tetrahedral intermediate. In fact, we believe that it is the determining factor.

\section{REFERENCES}

1 (a) M. L. Bender, Chem. Rev. 60, 53 (1960).

(b) S. L. Johnson in Advances in Physical Organic Chemistry, Vol. 5, pp 237-331. U. Gold (ed.), Academic Press: London (1967).

2 (a) P. Deslongchamps and C. Moreau, Canad. J. Chem. 49, 2465 (1971).

(b) P. Deslongchamps, C. Moreau, D. Fréhel and P. Atlani, Canad. J. Chem. 50, 3402 (1972).

3 P. Deslongchamps, P. Atlani, D. Fréhel and A. Malaval, Canad. J. Chem. 50, 3405 (1972).

4 P. Deslongchamps, C. Lebreux and R. J. Taillefer, Canad. J. Chem. 51, 1665 (1973).

${ }^{5}$ R. U. Lemieux in Molecular Rearrangements, Pt 2. P. de Mayo (ed.), Interscience: New York (1964).

R. U. Lemieux, Abstract of Papers, J. Amer. Chem. Soc. 135, 5E (1959).

R. U. Lemieux, Pure Appl. Chem. 25, 527 (1971).

6 O. Exner, V. Jehliča and B. Uchytil, Coll. Czech. Chem. Commun. 33, 2862 (1968).

7 R. Huisgen and H. Ott, Tetrahedron, 6, 253 (1959).

8 J. E. Blackwood, C. L. Gladys, K. L. Loening, A. E. Petrarca and J. E. Rush, J. Amer. Chem. Soc. 90, 509 (1968).

9 E. H. Cordes in Progress in Physical Organic Chemistry, Vol. 4, pp 1-44. A. Streitwieser and R. W. Taft, (eds), Interscience: New York (1967).

10 R. Chênevert and C. Moreau. Unpublished results, this laboratory.

11 B. G. Ramsey and R. W. Taft, J. Amer. Chem. Soc. 88, 3058 (1966).

12 (a) T. Okuyama, T. C. Pletcher, D. J. Sahn and G. L. Schmir, J. Amer. Chem. Soc. 95, 1253 (1973) and references quoted therein.

(b) P. Allen Jr and J. Ginos, J. Org. Chem. 28, 2759 (1963).

13 M. Eigen, Angew. Chem. Internat. Edit. 3, 1 (1964). 